\title{
Membrane topology and mutational analysis of the osmotically activated BetT choline transporter of Escherichia coli
}

Correspondence

Anne Tøndervik

Anne.Tondervik@biotech.ntnu.no

Received 20 October 2006

Revised 27 November 2006

Accepted 29 November 2006

\section{Anne Tøndervik and Arne R. Strøm}

Department of Biotechnology, The Norwegian University of Science and Technology, N-7491 Trondheim, Norway

\begin{abstract}
For osmoprotection, Escherichia coli can synthesize glycine betaine from externally supplied choline by the Bet system (betTIBA products). The major carrier of choline is the high-affinity, proton-driven, secondary transporter BetT, which belongs to the BCCT family of transporters. Fusion proteins consisting of $\mathrm{N}$-terminal fragments of BetT linked to $\beta$-galactosidase (LacZ) or alkaline phosphatase (PhoA) were constructed. By analysis of 51 fusion proteins with 37 unique fusion-points, the predictions that BetT comprised 12 membrane-spanning regions and that its $\mathrm{N}$ - and $\mathrm{C}$-terminal extensions of about 12 and 180 amino acid residues, respectively, were situated in the cytoplasm were confirmed. This is believed to represent the first experimental examination of the membrane topology of a BCCT family protein. Osmotic upshock experiments were performed with spectinomycin-treated $E$. coli cells that had expressed the wild-type or a mutant BetT protein during growth at low osmolality $\left(160 \mathrm{mosmol} \mathrm{kg}{ }^{-1}\right)$. The choline transport activity of wild-type BetT increased tenfold when the cells were stressed with $0.4 \mathrm{M} \mathrm{NaCl}$ (total osmolality 780 mosmol kg ${ }^{-1}$ ). The peak activity was recorded 5 min after the upshock and higher or lower concentrations of $\mathrm{NaCl}$ reduced the activity. Deletions of 1-12 C-terminal residues of BetT caused a gradual reduction in the degree of osmotic activation from ten- to twofold. Mutant proteins with deletion of 18-101 residues displayed a background transport activity, but they could not be osmotically activated. The data showed that the cytoplasmic C-terminal domain of BetT plays an important role in the regulation of BetT activity and that $\mathrm{C}$-terminal truncations can cause BetT to be permanently locked in a low-transport-activity mode.
\end{abstract}

\section{INTRODUCTION}

Escherichia coli adapts to environments of elevated osmotic strength by accumulation of potassium glutamate together with compatible solutes. The organism has two wellcharacterized transporters, ProU and ProP, for uptake of the compatible solutes glycine betaine, proline and ectoine. ProU is an ATP-binding cassette (ABC) transporter (May et al., 1986), whereas ProP is a secondary transporter driven by the proton-motive force. ProP belongs to the major facilitator superfamily and possesses a large cytoplasmic Cterminal domain (Culham et al., 2000; Zoetewey et al., 2003). These transporters are osmotically activated at both the transcriptional and post-translational levels. E. coli also has two metabolic pathways for the synthesis of compatible solutes. These are the osmoregulated Ots system for UDPglucose-dependent synthesis of trehalose (Giæver et al., 1988 ) and the Bet system for synthesis of glycine betaine from externally supplied choline (Landfald \& Strøm, 1986).

Abbreviation: ABC, ATP-binding cassette; XP, 5-bromo-4-chloro-3indolyl phosphate.
The bet regulon comprises three structural genes: bet $T$ encoding a choline transporter, betA encoding choline dehydrogenase and betB encoding betaine aldehyde dehydrogenase. In addition, betI encodes a DNA-binding and choline-sensing regulator. The betIBA and the bet T genes are divergently organized and the promoters of betI and bet $T$ overlap (Lamark et al., 1991, 1996; Røkenes et al., 1996).

BetT is a proton-driven secondary transporter (Lamark et al., 1991) belonging to the BCCT family which comprises transporters for quaternary ammonium compounds. These transporters are predicted to have 12 membrane-spanning regions and to have their hydrophilic $\mathrm{N}$ - and C-termini located in the cytoplasm (Saier et al., 1999). However, the membrane topology has not been tested experimentally for any such transporter. In this investigation, we have therefore probed and verified this domain structure of Bet $\mathrm{T}$ by constructing a series of fusion proteins with C-terminally linked alkaline phosphatase (PhoA) or $\beta$-galactosidase (LacZ). This analysis is based on the well-established fact that the PhoA moiety of hybrid proteins displays phosphatase activity only when translocated to the periplasmic space 
(Manoil \& Beckwith, 1986), whereas the LacZ moiety must remain in the cytoplasm to be enzymically active (Froshauer et al., 1988).

The homologous Bet T transporters for choline of $E$. coli (Andresen et al., 1988) and Haemophilus influenzae (Fan et al., 2003) are activated at the level of transport by osmotic stress, despite the fact that choline is not a compatible solute per se (Styrvold et al., 1986). These transporters seem to have much the same properties as glycine betaine transporters of the BCCT family; e.g. BetP of Corynebacterium glutamicum (Farwick et al., 1995), BetS of Sinorhizobium meliloti (Boscari et al., 2002) and OpuD of Bacillus subtilis (Kappes et al., 1996). However, there are intriguing differences between these transporters that do not reflect their substrate specificity. BetS (Boscari et al., 2002) and the two BetT transporters (Lamark et al., 1991; Fan et al., 2003; present study) have a large deduced C-terminal domain comprising about 170-180 amino acid residues, whereas this domain of OpuD (Kappes et al., 1996) and BetP (Peter et al., 1996) comprises only about 30 and 60 residues, respectively. In addition, BetS and BetP have an N-terminal hydrophilic domain of about 50-60 residues, which is much larger than the ones found in the three other transporters.

ProP of E. coli (Racher et al., 1999), BetP of C. glutamicum (Rübenhagen et al., 2000) and the $\mathrm{ABC}$ transporter for glycine betaine, OpuA, of Lactococcus lactis (van der Heide \& Poolman, 2000) have been purified and reconstituted into liposomes and shown to work as both osmosensors and osmoregulators independently of other proteins. Although these transporters are widely different, they all respond to the osmotic conditions in the cytoplasm and the lumen of liposomes. Only ionic osmolytes (particularly $\mathrm{K}^{+}$) activate OpuA and BetP (van der Heide et al., 2001; Rübenhagen et al., 2001), whereas ProP also responds to organic molecules in a size-dependent manner (Culham et al., 2003). BetP is a trimer in the cytoplasmic membrane and each monomer is predicted to have a transport pathway (Ziegler et al., 2004). ProP exists in monomer-dimer equilibrium in vivo and dimerization may be mediated by the formation of a C-terminal antiparallel coiled-coil structure which stabilizes ProP in an active conformation (Hillar et al., 2005).

The osmotic activation of E. coli BetT has not previously been studied in detail. In this investigation, we have characterized the in vivo transport activity of wild-type Bet $T$ and Bet $\mathrm{T}$ mutant proteins carrying deletions or amino acid substitutions in the C-terminal hydrophilic domain. Whereas C-terminal deletions of BetP of C. glutamicum led to permanent activation of this glycine betaine transporter (Peter et al., 1998; Morbach \& Krämer, 2003), deletions of 18-101 amino acid residues of BetT locked it in a low-activity state of choline transport.

\section{METHODS}

Bacterial strains, plasmids and phage. These are listed in Tables 1,3 and 4 .
Growth media. The rich medium used was LB. The minimal media used were medium 63 (M63) with $0.4 \%(\mathrm{v} / \mathrm{w})$ glucose and halfstrength M63 (Miller, 1972). The latter medium contained half the amount of the inorganic salts and the full amount of glucose. The osmotic strength of the media was increased by addition of $\mathrm{NaCl}$ or sucrose as stated in the text. LB agar containing the indicator dye 5bromo-4-chloro-3-indolyl phosphate (XP; $40 \mu \mathrm{g} \mathrm{ml}^{-1}$ ) was used for selection of strains with alkaline phosphatase activity (Manoil, 1991). When required, ampicillin (Amp; $100 \mu \mathrm{g} \mathrm{ml}^{-1}$ ), chloramphenicol $\left(\mathrm{Chl} ; 30 \mu \mathrm{g} \mathrm{ml}^{-1}\right)$ or tetracycline (Tet; $15 \mu \mathrm{g} \mathrm{ml}^{-1}$ ) was added to the media.

Standard molecular biology techniques and strain constructions. Restriction endonuclease digestion, ligation and agarose gel electrophoresis of DNA were performed in accordance with standard protocols (Sambrook et al., 1989). Plasmid DNA was prepared by the midi-kit from Qiagen or the Wizard miniprep kit from Promega. DNA was extracted from agarose gels using the Qiaex or the Qiaquick kit from Qiagen. DNA sequencing was performed using cycle sequencing with the AmpliTaq kit from PE Applied Biosystems. PCR was performed utilizing the Expand High Fidelity PCR System from Roche or the PfuTurbo DNA polymerase from Stratagene. DH5 $\alpha$ was used as a standard transformation host and transformation was performed by the method of Chung et al. (1989) or by electroporation as described by Hanahan et al. (1991). By selecting for $\mathrm{Tet}^{\mathrm{R}}$ and scoring for $\mathrm{LacZ}^{-}$phenotype, $\Delta(\operatorname{argF}-$ lac) U169 and zah::Tn10 of SH205 was cotransduced by P1 into strain JP8442 by the method described by Miller (1972). The Tet ${ }^{\mathrm{R}}$ marker was deleted from the resulting transductant (AT100) by using the method described by Bochner et al. (1980), yielding strain AT101. Strain AT300 was constructed by deleting the Tet $^{\mathrm{R}}$ marker in MHK-1 by using the same method (Table 1$)$. The $\Delta(\operatorname{argF}-$ lac) U169 deletion encompasses the betTIBA gene cluster.

Construction of betT-phoA fusion plasmids. The BspHI site of the low-copy-number vector pACYC184 was filled in using Klenow polymerase, and the $p h o A$ gene from pUI310 was then ligated as a $1.5 \mathrm{~kb}$ HindIII-BanII fragment into the same sites of the vector. The bet $T$ gene from pFF221 was then ligated as a $2.7 \mathrm{~kb} P v u \mathrm{II}-X m n \mathrm{I}$ fragment into the HindIII site, which was first made blunt by Klenow polymerase. The resulting plasmid pAT3 carried bet $T$ including its stop codon upstream of a signal-less and unexpressed phoA reporter gene, separated by a linker containing BspHI, PstI, $\mathrm{Xba \textrm {I }}$ and $\mathrm{BamHI}$ restriction sites in that order. These sites together with the $X b a \mathrm{I}$ and $P v u \mathrm{I}$ sites upstream of $b e t T$, the $S f_{c I}, B s i \mathrm{WI}$ and $N d e$ I sites within betT and a $K p n I$ site downstream of $p h o A$ were used for construction of plasmids with in-frame bet $T-p h o A$ fusions, using methods 1 to 3 described below. The constructed plasmids can be identified by their fusion-point numbers listed in Table 3 .

1. Random deletions. pAT3 was linearized with BspHI and PstI to create a $5^{\prime}$ overhang downstream of betT and a $3^{\prime}$ overhang protected from exonuclease activity upstream of phoA. Time-dependent exonuclease III (Erase-a-base kit, Promega) treatment was then applied to introduce $3^{\prime}$ deletions in betT. The resulting pAT3 fragments were then blunted with S1 nuclease and Klenow DNA polymerase before recircularization with T4 DNA ligase and transformation into strain AT101. Plasmids from transformants forming blue colonies on XP indicator plates were analysed by restriction digestion and DNA sequencing, thereby identifying fusion-point numbers $2,4-10,12-17$, 19-24, 26 and 28-32 (Table 3).

2. PCR based constructions. To create fusion-point number 37, a PCR fragment was amplified from pAT3 using primer pair 1 (Table 2). One primer was homologous to a region upstream of the NdeI site in betT and the second introduced a BamHI site over the last coding triplet and also a silent mutation (GAC $\rightarrow$ GAT) in the Asp- 676 codon of bet T. PCR-amplified DNA was cloned as a NdeI-BamHI fragment into the 
Table 1. E. coli strains, bacteriophage and plasmids used in the construction procedures

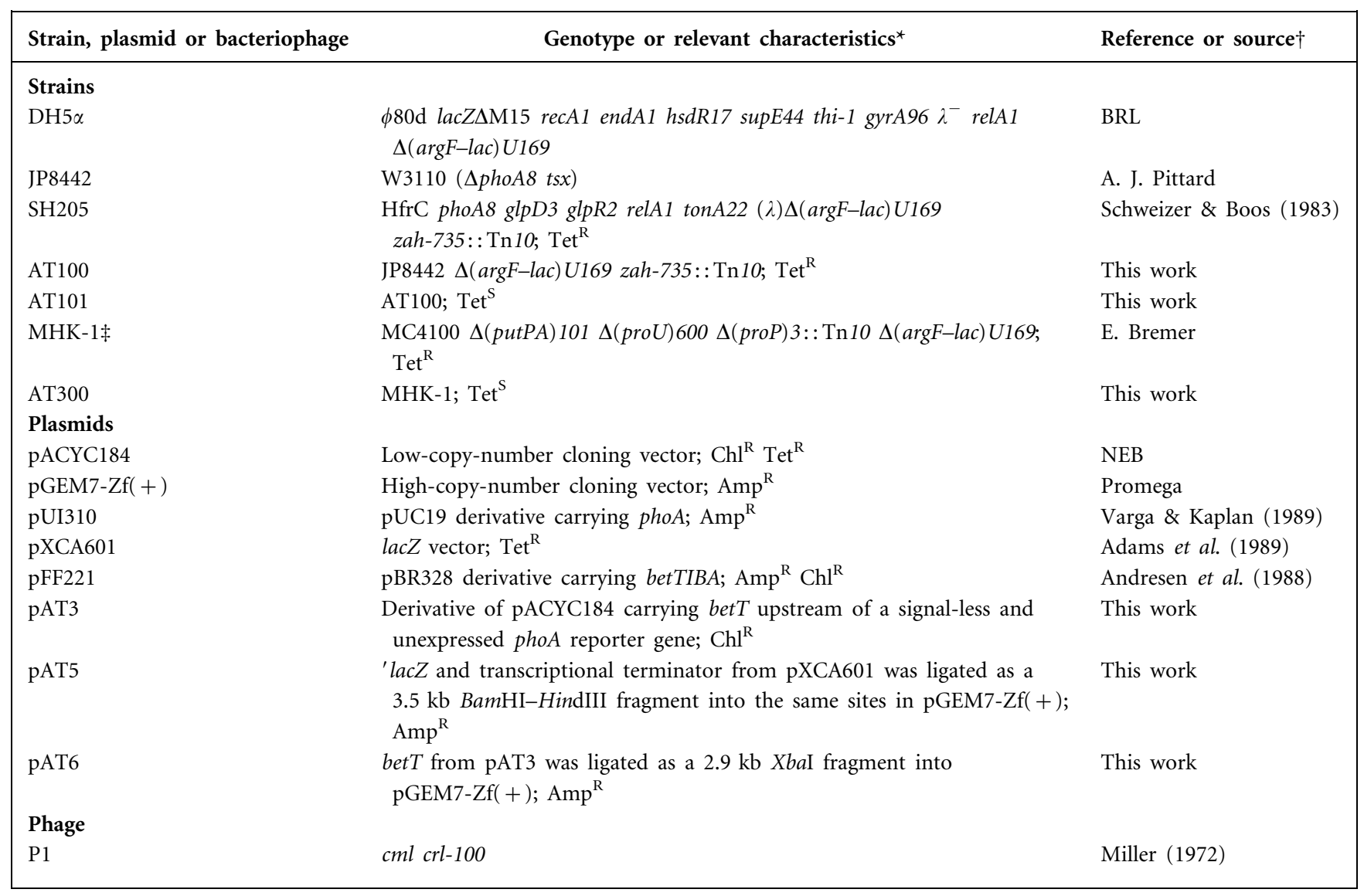

${ }^{\star} A \mathrm{Ap}^{\mathrm{R}}$, ampicillin resistance; $\mathrm{Chl}^{\mathrm{R}}$, chloramphenicol resistance; $\mathrm{Tet}^{\mathrm{R}}$, tetracycline resistance.

$\dagger$ A. J. Pittard, University of Melbourne, Australia; BRL, Bethesda Research Laboratories; E. Bremer, Philipps University Marburg, Germany; NEB, New England Biolabs.

$\ddagger$ The $\Delta(\arg F-l a c) U 169$ deletion encompasses the betTIBA gene cluster.

same sites of pAT3, thereby replacing the original bet $T$ fragment. For generation of fusion-point numbers 1, 3, 11, 18 and 27, BamHI sites were introduced at other locations in bet $T$ by using primer pairs 2 to 6 . The first oligo in each pair was identical and could bind upstream of the $P v u$ I site preceding betT. The PCR-generated fragments were digested with $P v u \mathrm{I}$ and BamHI and cloned into the same sites of pAT3. Fusionpoint number 36 was constructed using the QuickChange SiteDirected Mutagenesis Kit (Stratagene). A BamHI site was introduced just downstream of betT codon number 653 in pAT6 using primer pair 7. A BsiWI-BamHI fragment of PCR-amplified DNA was then cloned into the same sites of pAT3. The PCR amplified parts of these fusion plasmids were sequenced.

3. Use of restriction sites. pAT3 was linearized by digestion with the restriction enzymes $S f c \mathrm{I}-P s t \mathrm{I}, B s i \mathrm{WI}-B a m \mathrm{HI}$ or NdeI-PstI. The pAT3 fragments were treated with T4- or Klenow DNA polymerase before religation, thereby creating fusion-point numbers 25,33 and 35 . The junctions of these plasmids were sequenced. Fusion plasmids generated by methods 2 and 3 were finally transformed into strain AT101.

Construction of betT-lacZ fusion plasmids. A lacZ gene derivative without the eight first codons was excised as a $3.5 \mathrm{~kb}$ BamHI$K p n I$ fragment from pAT5 and ligated into the same sites of selected pAT3-derived plasmids, thereby replacing their in-frame betT-phoA with an in-frame betT-lacZ at fusion-points 1, 3, 11, 12, 18, 20, 22,
23, 27, 31, 32 and 35-37 (Table 3). To create an in-frame betT-lacZ fusion at point number 34 , we used the QuickChange strategy to introduce a BamHI site just downstream of codon 576 of the betT gene by using primer pair 8 and pAT6. The resulting mutant betT fragment was cloned as a $\mathrm{XbaI}$ fragment into pAT3 linearized with the same enzyme. The resulting plasmid was then cut with BamHI and KpnI and joined with the lacZ-containing fragment from pAT5. The plasmids were finally transformed into strain AT101.

C-terminal deletions and amino acid substitutions in BetT. The QuickChange mutagenesis strategy was applied to introduce stop codons at selected sites in bet $T$. The procedures were performed with primer pairs 9-16 (Table 2) using pAT6 as template. The resulting plasmids encoded BetT proteins with C-terminal deletions of 1-101 residues. The mutant betT genes were first cloned as $\mathrm{Xba \textrm {I }}$ fragments into pAT3, and to limit the necessary DNA sequencing the BsiWI-BamHI fragments carrying the mutated $3^{\prime}$ ends of betT were again subcloned into pAT3. Mutant BetT proteins with Cterminal amino acid substitutions were made by the same strategy using the primer pairs 17-19. The plasmids were finally transformed into strain AT300. The plasmids constructed and the characteristics of the BetT mutant proteins are listed in Table 4.

Enzyme assays. Alkaline phosphatase activity of cells was assayed by measuring the rate of $p$-nitro phenyl phosphate hydrolysis as 
Table 2. Primers used for construction of BetT fusions and BetT mutants with deletions or substitutions

\begin{tabular}{|c|c|c|}
\hline $\begin{array}{l}\text { Primer } \\
\text { pair }\end{array}$ & $\begin{array}{l}\text { Fusion-point no. } \\
\text { or Bet } T \text { construct }\end{array}$ & Sequence $\left(5^{\prime} \rightarrow 3^{\prime}\right) \dagger$ \\
\hline 1 & 37 & $\begin{array}{l}\text { GTCATCTGGATTTGTTGG } \\
\text { AATCaAGgaTCCGGGAACATCA }\end{array}$ \\
\hline 2 & 1 & $\begin{array}{l}\text { CCCTGAAATAGTGGCTGATG (Fwd2) } \\
\text { CACCACCGGATccATTTTGT }\end{array}$ \\
\hline 3 & 3 & $\begin{array}{l}\text { Fwd2 } \\
\text { CAGGCTGggaTCCGGTTTG }\end{array}$ \\
\hline 4 & 11 & $\begin{array}{l}\text { Fwd2 } \\
\text { CCACTGAGgGAtCcATCGG }\end{array}$ \\
\hline 5 & 18 & $\begin{array}{l}\text { Fwd2 } \\
\text { CGCGACATTAgGaTCCGATA }\end{array}$ \\
\hline 6 & 27 & $\begin{array}{l}\text { Fwd2 } \\
\text { TCTTTAgGatCCGAGGTGAA }\end{array}$ \\
\hline 7 & 36 & $\begin{array}{l}\text { CCGATATTCTTGACCAGgAtccGCGGCACCTTAAC } \\
\text { GTTAAGGTGCCGCggaTcCTGGTCAAGAATATCGG }\end{array}$ \\
\hline 8 & 34 & $\begin{array}{l}\text { AAGCCTGCCACCGGAtcctGGACAGCAGTTGGGTC } \\
\text { GACCCAACTGCTGTCCaggaTCCGGTGGCAGGCTT }\end{array}$ \\
\hline 9 & BetT676 & $\begin{array}{l}\text { CGGACtaGTGATTGTTATTG } \\
\text { CAATAACAATCACtaGTCCG }\end{array}$ \\
\hline 10 & BetT675 & $\begin{array}{l}\text { TGTTCCCGtAaGCGTGATTG } \\
\text { CAATCACGCtTaCGGGAACA }\end{array}$ \\
\hline 11 & BetT671 & $\begin{array}{l}\text { GTGAAGCGCCGGGCCATAGCtaGATGTTCC } \\
\text { GGAACATCtaGCTATGGCCCGGCGCTTCAC }\end{array}$ \\
\hline 12 & BetT665 & $\begin{array}{l}\text { CATCTCCATCGTtAAGCGCCGGGCCATAGC } \\
\text { GCTATGGCCCGGCGCTTaACGATGGAGATG }\end{array}$ \\
\hline 13 & BetT659 & $\begin{array}{l}\text { GCGGCACCTTAACTgaATTCATCTCCATCG } \\
\text { CGATGGAGATGAATtcAGTTAAGGTGCCGC }\end{array}$ \\
\hline 14 & BetT653 & $\begin{array}{l}\text { CGATATTCTTGACCAGTAgGAGCGGCACC } \\
\text { GGTGCCGCTCcTACTGGTCAAGAATATCG }\end{array}$ \\
\hline 15 & BetT590 & $\begin{array}{l}\text { GATTTGTTGGTGCATtaGGGCGAAGAG } \\
\text { CTCTTCGCCCtaATGCACCAACAAATC }\end{array}$ \\
\hline 16 & BetT576 & $\begin{array}{l}\text { GCCTGCCACCGtAAGAGGGACAGC } \\
\text { GCTGTCCCTCTTaCGGTGGCAGGC }\end{array}$ \\
\hline 17 & BetT677-V672A-M673A & $\begin{array}{l}\text { CCATAGCGcGgcGTTCCCGGACGCGTGATT } \\
\text { AATCACGCGTCCGGGAACgcCgCGCTATGG }\end{array}$ \\
\hline 18 & BetT677-M673A-F674A & $\begin{array}{l}\text { GCCATAGCGTGgcGgcCCCGGACGCGTGATTG } \\
\text { CAATCACGCGTCCGGGgcCgcCACGCTATGGC }\end{array}$ \\
\hline 19 & BetT677-F674A-P675A-D676G & $\begin{array}{l}\text { CCGGGCCATAGCGTGATGgcCgCaGcCGCGTGATTG } \\
\text { CAATCACGCGgCtGcGgcCATCACGCTATGGCCCGG }\end{array}$ \\
\hline
\end{tabular}

${ }^{*}$ As referred to in Tables 3 and 4 .

$\dagger$ The forward primer in pairs $2-6$ is identical (Fwd2). Restriction sites, stop codons and changed triplets are underlined. Nucleotides differing from wild-type bet $T$ are indicated by lower-case letters.

described by Manoil (1991). The cells were grown at $37^{\circ} \mathrm{C}$ in LB to an $\mathrm{OD}_{600}$ of $0.5-1.0$. To prevent the slow activation of cytoplasmic forms of alkaline phosphatase in non-growing cells, iodoacetamide was added to the assay mixture at a final concentration of $1 \mathrm{mM}$ (Derman \& Beckwith, 1995). $\beta$-Galactosidase activity was assayed by measuring the rate of hydrolysis of $o$-nitrophenyl $\beta$-D-galactoside as described by Miller (1972). The cells were grown at $37^{\circ} \mathrm{C}$ in LB or half-strength M63 to an $\mathrm{OD}_{600}$ of $0.5-1.0$ and then permeabilized by treatment with SDS and chloroform. Units of enzyme activity were calculated according to the references cited above. The values given in Table 3 are the means of duplicate determinations from at least three independent cultures and standard deviation from the mean was in general less than $20 \%$.

BetT-PhoA fusion protein levels. To determine the expression level of the fusion proteins, whole cells were subjected to SDS-PAGE and Western blotting. The cells were grown in M63 to an $\mathrm{OD}_{600}$ of $0.5-1.0$, harvested and resuspended in $50 \mathrm{mM}$ Tris $\mathrm{pH} 8.0$ to an $\mathrm{OD}_{600}$ of 20 . Then $20 \mu \mathrm{l}$ samples of this suspension were separated by SDS-7.5\% PAGE and proteins were transferred $(1 \mathrm{~h}$ at $80 \mathrm{~V})$ to 
Table 3. Description and enzyme activities of BetT-PhoA and BetT-LacZ fusion proteins

\begin{tabular}{|c|c|c|c|}
\hline Fusion-point no. & Last Bet $\mathrm{T}$ residue & $\begin{array}{l}\text { Alkaline phosphatase } \\
\text { activity (Rel. U) }\end{array}$ & $\beta$-Galactosidase activity (Rel. U) $\dagger$ \\
\hline 1 & Lys-12 & 0 & $910(7400)$ \\
\hline 2 & Gly 44 & 100 & $-\ddagger$ \\
\hline 3 & Pro-89 & 0 & $160(1700)$ \\
\hline 4 & Gly 106 & 110 & - \\
\hline 5 & Met-110 & 100 & - \\
\hline 6 & Gln-130 & 130 & - \\
\hline 7 & Ala-135 & 90 & - \\
\hline 8 & Gln-137 & 120 & - \\
\hline 9 & Ala-138 & 130 & - \\
\hline 10 & Trp-141 & 100 & - \\
\hline 11 & Pro-189 & 0 & $150(1200)$ \\
\hline 12 & Ala-207 & 60 & $50(670)$ \\
\hline 13 & Leu-210 & 100 & - \\
\hline 14 & Gly 211 & 140 & - \\
\hline 15 & Ser-230 & 140 & - \\
\hline 16 & Ala-232 & 160 & - \\
\hline 17 & Ala-235 & 160 & - \\
\hline 18 & Ser-261 & 0 & $170(1400)$ \\
\hline 19 & Leu-273 & 120 & - \\
\hline 20 & Leu-276 & 170 & $0(0)$ \\
\hline 21 & Gly 301 & 180 & - \\
\hline 22 & Ala-339 & 1 & $40(430)$ \\
\hline 23 & Ser-367 & 180 & $0(0)$ \\
\hline 24 & His-379 & 130 & - \\
\hline 25 & Tyr-397 & 160 & - \\
\hline 26 & Gln-402 & 180 & - \\
\hline 27 & Ser- 437 & 0 & $110(1500)$ \\
\hline 28 & Met-467 & 170 & - \\
\hline 29 & Ala-473 & 220 & - \\
\hline 30 & Asn- 476 & 210 & - \\
\hline 31 & Leu- 483 & 190 & 0 \\
\hline 32 & Ala-494 & 1 & $60(660)$ \\
\hline 33 & Tyr-568 & 0 & - \\
\hline 34 & Pro-576 & - & $300(2800)$ \\
\hline 35 & His-590 & 0 & $280(2600)$ \\
\hline 36 & Gln-653 & 0 & $270(1900)$ \\
\hline 37 & Asp-676 & 0 & $270(2400)$ \\
\hline
\end{tabular}

${ }^{\star}$ The relative units (Rel. U) of phosphatase activity were calculated as described by Manoil (1991). The cells were grown in LB.

$\dagger$ The relative units (Rel. U) of $\beta$-galactosidase activity were calculated as described by Miller (1972). The cells were grown in LB or half-strength M63 (numbers in parentheses).

$\ddagger-$, Constructs not made.

a nitrocellulose membrane (Millipore). The membrane was blocked with $1 \%$ skim milk powder in Tris-buffered saline $(20 \mathrm{mM}$ Tris/ $\mathrm{HCl}, \mathrm{pH} 7.5,150 \mathrm{mM} \mathrm{NaCl}$ ) before detection of BetT-PhoA fusion proteins with rabbit anti-E. coli alkaline phosphatase (Polysciences) as the primary antibody. Goat anti-rabbit IgG conjugated to alkaline phosphatase (Sigma) was used as the secondary antibody and BCIP/ NBT Blue (Sigma) was used as the liquid substrate. The BetT-PhoA fusion proteins tested are stated in the text.
Transport measurements. Strain AT300 carrying the relevant plasmids was grown at $37^{\circ} \mathrm{C}$ in half-strength M63 or in M63 supplemented with $0.3 \mathrm{M} \mathrm{NaCl}$ to an $\mathrm{OD}_{600}$ of $0.4-0.6$. Spectinomycin was added to a final concentration of $1 \mathrm{mg} \mathrm{ml}^{-1}$ to prevent further protein synthesis, and the cultures were maintained at room temperature for no longer than $2 \mathrm{~h}$ prior to the transport assay. The choline transport capacity of the cells was activated by addition of $\mathrm{NaCl}$ or sucrose at $37^{\circ} \mathrm{C}$; the solute concentrations (up to $0.8 \mathrm{M}$ ) 
Table 4. Osmotic activation of choline uptake in E. coli expressing wild-type BetT or BetT mutants with C-terminal deletions or amino acid substitutions

\begin{tabular}{|c|c|c|c|c|c|}
\hline \multirow[t]{2}{*}{ Plasmid } & \multirow[t]{2}{*}{$\begin{array}{l}\text { Description of BetT } \\
\text { protein expressed }\end{array}$} & \multicolumn{2}{|c|}{$\begin{array}{c}\text { Initial rate of choline } \\
\text { uptake }\left[\mathrm{nmol} \mathrm{min}^{-1}\right. \\
\left.(\mathrm{mg} \text { protein })^{-1}\right]^{*} \text { when tested in } \dagger:\end{array}$} & \multicolumn{2}{|c|}{$\begin{array}{l}\text { Choline accumulated at steady-state level } \\
{\left[\mathrm{nmol}(\mathrm{mg} \text { protein })^{-1}\right] \ddagger \text { when tested in } \S:}\end{array}$} \\
\hline & & $\begin{array}{l}\text { Half-strength } \\
\text { M63 }\end{array}$ & $\begin{array}{l}\text { Half-strength } \mathrm{M} 63 \\
\quad+0.4 \mathrm{M} \mathrm{NaCl}\end{array}$ & $\begin{array}{l}\text { Half-strength } \\
\text { M63 }\end{array}$ & $\begin{array}{l}\text { Half-strength M63 } \\
\quad+0.4 \mathrm{M} \mathrm{NaCl}\end{array}$ \\
\hline pAT3 & BetT677 (wild-type) & $19 \pm 3$ & $181 \pm 11$ & 36 & 360 \\
\hline pAT101 & $\operatorname{BetT676}(\Delta 1)$ & $16 \pm 6$ & $162 \pm 19$ & 23 & 310 \\
\hline pAT102 & BetT675 $(\Delta 2)$ & $15 \pm 5$ & $162 \pm 19$ & 23 & 340 \\
\hline pAT103 & $\operatorname{BetT671}(\Delta 6)$ & $16 \pm 3$ & $88 \pm 15$ & 31 & 160 \\
\hline pAT104 & $\operatorname{BetT665}(\Delta 12)$ & $15 \pm 3$ & $36 \pm 5$ & 18 & 52 \\
\hline pAT105 & $\operatorname{BetT659}(\Delta 18)$ & $15 \pm 6$ & $12 \pm 3$ & 17 & 23 \\
\hline pAT106 & $\operatorname{BetT653}(\Delta 24)$ & $14 \pm 5$ & $12 \pm 4$ & 14 & 17 \\
\hline pAT107 & $\operatorname{BetT590}(\Delta 87)$ & $14 \pm 6$ & $14 \pm 4$ & 12 & 12 \\
\hline pAT108 & $\operatorname{BetT576}(\Delta 101)$ & $9 \pm 3$ & $14 \pm 6$ & 12 & 16 \\
\hline pAT109 & BetT677-V672A-M673A & $19 \pm 8$ & $128 \pm 10$ & 23 & 210 \\
\hline pAT110 & BetT677-M673A-F674A & $19 \pm 5$ & $67 \pm 6$ & 20 & 93 \\
\hline pAT111 & BetT677-F674A-P675A-D676G & $12 \pm 2$ & $78 \pm 11$ & 20 & 65 \\
\hline
\end{tabular}

${ }^{\star}$ The values given are the means $\pm \mathrm{SD}$ of at least ten determinations from two to four separate cell cultures.

†Strain AT300 carrying the BetT expressing plasmids was grown in half-strength M63 and tested for initial uptake rate under the same conditions, and when $0.4 \mathrm{M} \mathrm{NaCl}$ was added 5 min prior to the addition of choline.

$\ddagger$ The standard deviations from the mean of the values given were within $\pm 15 \%$.

\$Steady-state levels of choline accumulation were based on at least five samples taken after incubation with substrate for at least 30 min.

and time periods (up to $20 \mathrm{~min}$ ) used are stated in the text. The uptake reaction was started by adding $\left[{ }^{14} \mathrm{C}\right]$ choline to the culture. The choline concentration routinely used was $200 \mu \mathrm{M}$; the specific

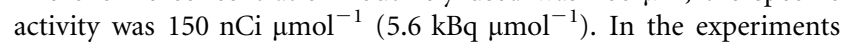
for measuring kinetic parameters, the specific activity of the substrates varied from 150 to $1500 \mathrm{nCi} \mu \mathrm{mol}^{-1}\left(5.6-56 \mathrm{kBq}^{\prime} \mathrm{mol}^{-1}\right)$ depending on the substrate concentration, which was varied from 2.5 to $50 \mu \mathrm{M}$. After time intervals as stated in the text, the reaction was stopped by withdrawal and filtration of 0.5 or $1.0 \mathrm{ml}$ samples. The filters (pore size $0.45 \mu \mathrm{m}$ ) were immediately washed once with $10 \mathrm{ml} \mathrm{M} 63$ containing $0.3 \mathrm{M} \mathrm{NaCl}$ and $0.5 \mathrm{M}$ sucrose. The filters were then solubilized in $5 \mathrm{ml}$ Filter-Count LSC cocktail (Packard) and the radioactivity was determined by liquid scintillation counting.

Other methods. Cell protein was determined by the Lowry method after treating the cells with $0.1 \mathrm{M} \mathrm{NaOH}$ at $95^{\circ} \mathrm{C}$ for $10 \mathrm{~min}$. Bovine serum albumin (fraction V, Sigma) was used as standard. The osmolality of growth media was measured as mosmol kg-1 by freezing-point depression.

\section{RESULTS}

\section{Predicted membrane topology of BetT}

Prediction of the topology (Fig. 1) of the BetT transporter (677 amino acid residues) was based on the TMHMM method, which takes into account the expected hydrophobicity of transmembrane regions and the abundance of positively charged residues on the cytoplasmic side of the membrane (Krogh et al., 2001). Other databases (e.g. National Center for Biotechnology Information) identify the same 12 transmembrane regions in Bet $\mathrm{T}$, but with slightly different boundaries.

\section{Investigation of the membrane topology by the use of PhoA and LacZ fusion proteins}

The low-copy-number plasmid pAT3 carried bet T with its native promoter upstream of an unexpressed $p h o A$ reporter gene which in a single cloning step could be replaced with a lac $Z$ reporter gene in the same reading frame. The betIBA operon was not present, except for a 201 bp region of betI. Random bet $T-p h o A$ fusions were made by joining the gene derivatives after unidirectional exonuclease digestion of the $3^{\prime}$ end of bet $T$ (see Methods). Transformants of strain AT101 displaying alkaline phosphatase activity were selected on indicator plates with the chromogenic substrate XP. The host organism AT101 carried $\triangle p h o A 8$ and $\Delta(\operatorname{argF-lac}) U 169$, which encompasses the betTIBA gene cluster. By analysis of plasmids from 24 dark blue and two light blue colonies, we identified 26 different in-frame fusion-points (Table 3, Fig. 1). Ten of them (numbers 2, 6-10, 15, 21, 24 and 30) were located in each of the six predicted periplasmic loops of BetT. Four (numbers 16, 17, 26 and 31) were located close to the periplasmic surface of putative 'incoming' transmembrane regions (N-termini pointing outwards). Thus PhoA was exported by the preceding transmembrane region. Ten (numbers 4, 5, 12-14, 19, 20, 23, 28 and 29) were located in putative 'outgoing' transmembrane regions and were preceded by at least nine native apolar residues. This 


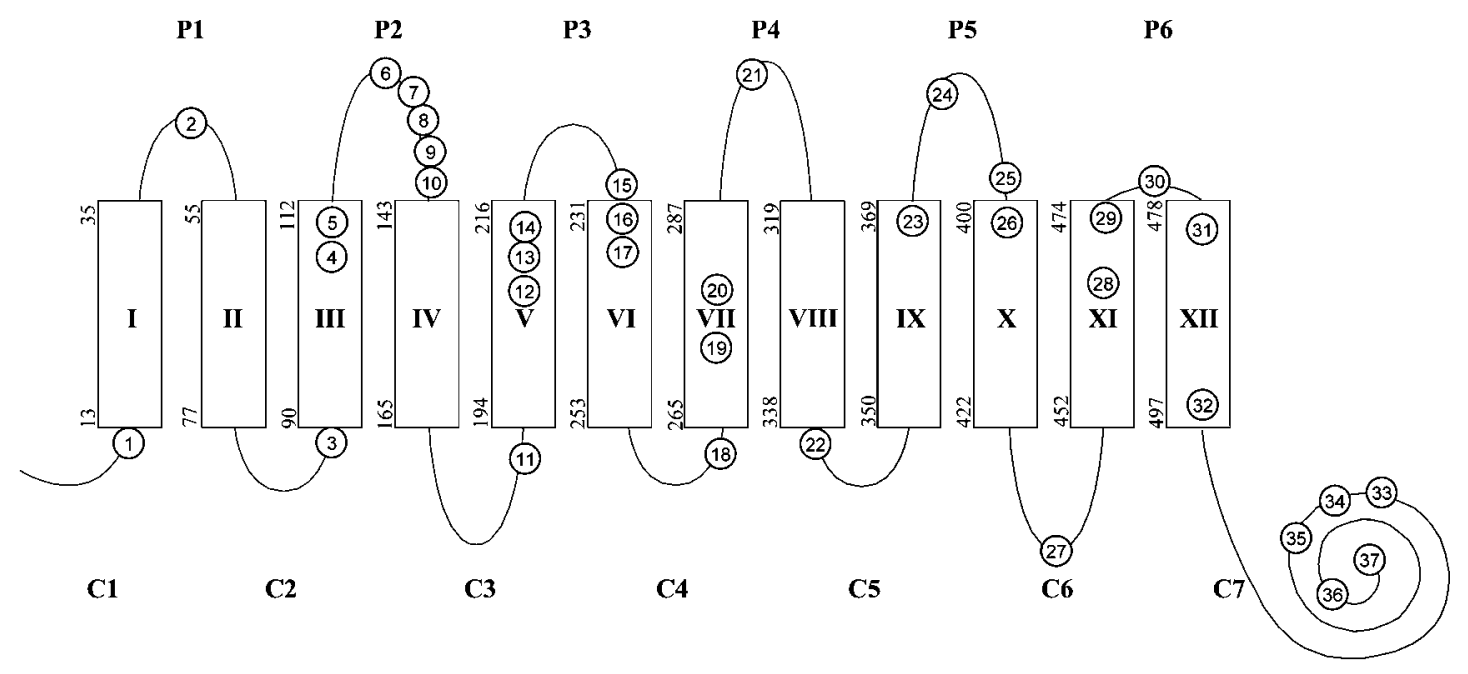

Fig. 1. Topological model of BetT. Membrane-spanning regions are shown as boxes numbered I to XII. The predicted BetT residues at the membrane boundaries are indicated with small numbers outside the boxes. $\mathrm{P} 1$ to $\mathrm{P} 6$ and $\mathrm{C} 1$ to $\mathrm{C} 7$ refer to the hydrophilic periplasmic and cytoplasmic segments, respectively. Circles numbered 1-37 indicate the point of fusion for BetT-PhoA and BetT-LacZ hybrid proteins as listed in Table 3.

number of apolar residues was previously reported to be sufficient for exporting the PhoA moiety of hybrid proteins to the periplasmic space (Calamia \& Manoil, 1990).

When grown in LB, 23 of the transformants selected as dark blue colonies displayed levels of alkaline phosphatase activity ranging from about 90 to above $200 \mathrm{U}$ (Table 3 ). The general tendency was that hybrid proteins with adjacent fusion-points displayed similar levels of activity and that their activity increased with the remaining length of BetT. In control experiments, we found that replacement of PhoA with LacZ at three of the fusion-points predicted to be in membrane-spanning regions (numbers 20, 23 and 31) gave hybrid proteins which did not confer $\beta$-galactosidase activity in cells grown in LB or half-strength M63.

An exception among fusion plasmids isolated from the dark blue colonies was the fusion-point number 12 (in membrane-spanning region number V; Fig. 1), which conferred an intermediate level of enzyme activity when fused with either PhoA or LacZ. Furthermore, the two betT-phoA transformants selected as light blue colonies on the XP indicator plates produced essentially no alkaline phosphatase activity when grown in LB medium. Their BetT-PhoA fusion-points were predicted to be in the cytoplasm (number 22 ) or near the cytoplasmic surface (number 32). Accordingly, the corresponding BetT-LacZ hybrid proteins displayed appreciable $\beta$-galactosidase activities (Table 3). However, cells producing these two LacZ hybrid proteins displayed reduced growth, even in rich medium.

The expression levels of 17 selected BetT-PhoA fusion proteins (numbers 2, 4, 6, 7, 12, 14, 15, 17, 19, 20-22, 24, 26, 28, 29 and 32) were determined by Western blotting using a primary antibody against the PhoA moiety. The fusion proteins displayed increasing apparent molecular mass according to the expectation. They were present in comparable amounts in all cases examined except for fusion numbers 22 and 32, which gave very faint signals on the membrane (data not shown). These two fusion proteins were presumably subjected to proteolytic degradation since PhoA can not be folded correctly in the reducing conditions of the cytoplasm.

We used alternative in vitro techniques (see Methods) to generate five fusion-points in the large hydrophilic Cterminal end of BetT (numbers 33-37) and one fusion-point in each of the other predicted cytoplasmic regions that were not probed by the first series of hybrid proteins (numbers 1 , 3, 11, 18 and 27). All BetT-PhoA hybrid proteins of this series were enzymically inactive when expressed in strain AT101, whereas the corresponding BetT-LacZ hybrids conferred a wide range of $\beta$-galactosidase activities to the host cells. The LacZ fusion with Lys-12 (number 1) was particularly active. For the remainder, the longer ones with fusion-points in the predicted C-terminal domain of BetT displayed the highest $\beta$-galactosidase activities.

\section{Osmotic activation of wild-type BetT}

Transport activity of plasmid encoded wild-type and mutant BetT proteins were measured in strain AT300, which carried the (argF-lac)U169 deletion, encompassing the betTIBA gene cluster (Table 1). This strain also carried deletions or mutations in all transporters for proline and glycine betaine, i.e. the measured choline uptake originates from the plasmid expressed bet $T$ genes.

As shown in Fig. 2(a), wild-type BetT was sufficiently expressed in strain AT300(pAT3) cells grown in 


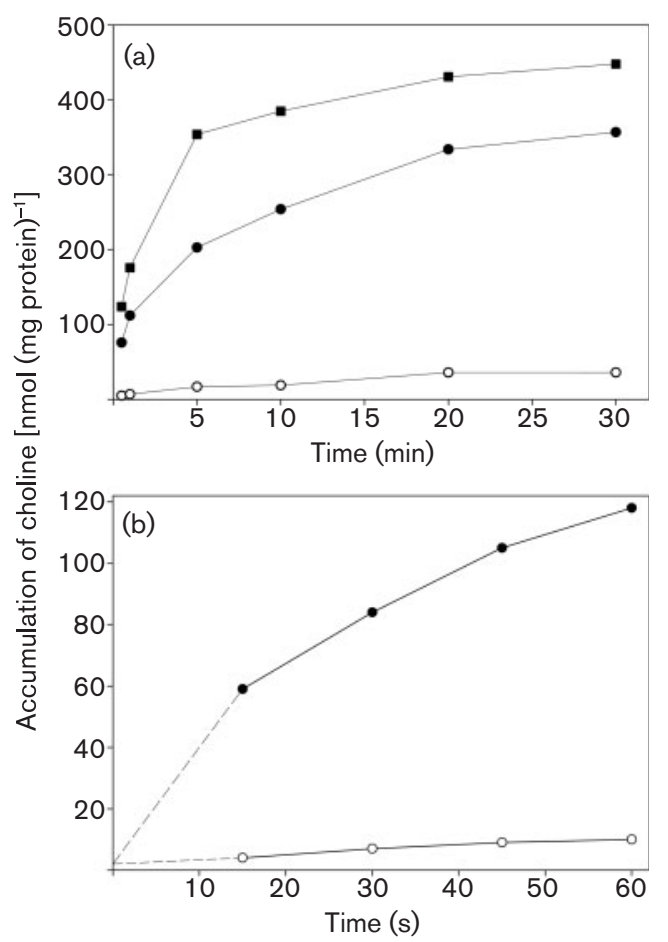

Fig. 2. Time-course of choline accumulation in strain AT300(pAT3) expressing wild-type BetT. Shown are the accumulation during a 30 min period (a) and during the first 1 min (b). $\bigcirc$, Cells grown and assayed in half-strength M63; $\square$, cells grown in half-strength $\mathrm{M} 63$ and exposed to $0.4 \mathrm{M} \mathrm{NaCl} 5$ min prior to the addition of choline; $\mathbf{\square}$, cells grown and assayed in full-strength $\mathrm{M} 63$ supplied with $0.3 \mathrm{M} \mathrm{NaCl}$. The dashed lines in (b) represent an extrapolation to time zero; see text. The curves shown are representative for each condition.

half-strength M63 (160 mosmol kg ${ }^{-1}$ ) to investigate the osmotic activation of the transporter; i.e. the uptake activity of spectinomycin-treated cells was greatly enhanced by addition of $0.4 \mathrm{M} \mathrm{NaCl}$ (total osmolality 780 mos$\mathrm{mol} \mathrm{kg}{ }^{-1}$ ) 5 min before the transport assay started (see below). Furthermore, cells grown and tested in M63 with $0.3 \mathrm{M} \mathrm{NaCl}\left(720\right.$ mosmol $\left.\mathrm{kg}^{-1}\right)$ displayed an even higher uptake activity, suggesting that the expression of the betT gene was stimulated by osmotic stress (Andresen et al., 1988). It should be noted that the choline uptake rate decreased gradually with time and the choline content of the cells reached a maximum within $30 \mathrm{~min}$. At this time, maximally $25 \%$ of the choline in the assay medium was taken up by the stressed cells; the start concentration was $200 \mu \mathrm{M}$.

As shown in Fig. 2(b), the gradual decrease in uptake rate was already noticeable during the first minute after the assay was started. Since the accumulation versus time curve was non-linear, we decided to define the initial uptake rate as the measured choline uptake after $30 \mathrm{~s}$. The apparent choline uptake in spectinomycin-treated cells of strain AT300(pACYC184; empty vector) was $2 \mathrm{nmol}$ (mg

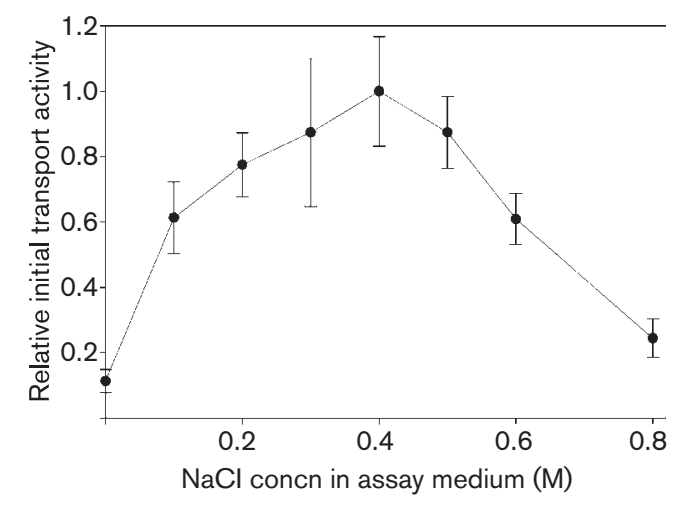

Fig. 3. Influence of the $\mathrm{NaCl}$ concentration on the relative initial uptake activity of wild-type BetT. Cells of AT300(pAT3) were grown in half-strength $\mathrm{M} 63$ and the indicated amounts of $\mathrm{NaCl}$ were added 5 min prior to choline. The initial uptake activity of cells exposed to $0.4 \mathrm{M} \mathrm{NaCl}$ was set as 1.0 , corresponding to $181 \mathrm{nmol} \mathrm{m^{-1 }}$ (mg protein) ${ }^{-1}$. The values given are the means $\pm S D$ of measurements from at least three separate cell cultures.

protein $)^{-1}$ (data not shown). This background of bound radioactivity, which was not influenced by the osmotic conditions or the length of the incubation time with choline, was therefore used as the value for accumulation at time zero. The values for initial rate of choline uptake reported in Table 4 and those used to make Figs 3 and 4, were the means of 10-25 measurements from two to four independent cell cultures.

The optimal $\mathrm{NaCl}$ concentration for activation of Bet $\mathrm{T}$ was $0.4 \mathrm{M}$; the transport activity decreased gradually at lower $(0.1-0.3 \mathrm{M})$ and higher $(0.5-0.8 \mathrm{M})$ salt concentrations

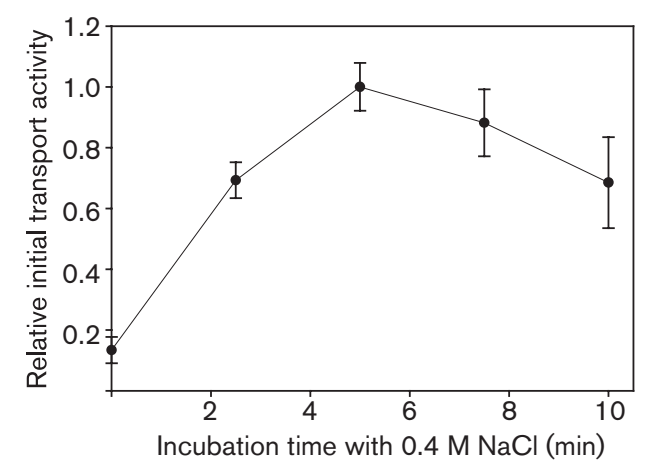

Fig. 4. Time-dependent activation of choline transport activity of wild-type BetT by $0.4 \mathrm{M} \mathrm{NaCl}$. Cells were grown in halfstrength M63 and exposed to osmotic stress for 0-10 min before the addition of choline. The initial uptake activity of cells exposed to $\mathrm{NaCl}$ for 5 min was set as 1.0 , corresponding to $181 \mathrm{nmol} \mathrm{m^{-1 }}$ (mg protein $)^{-1}$. The values given are the means $\pm S D$ of measurements from at least two separate cell cultures. 
(Fig. 3). Furthermore, the highest transport rate was observed $5 \mathrm{~min}$ after the cells were exposed to osmotic upshock. After that, the initial transport rate decreased $30 \%$ during the next 5 min (Fig. 4). The total activation of BetT by incubation with $0.4 \mathrm{M} \mathrm{NaCl}$ for 5 min was nearly tenfold; i.e. the initial transport rate increased from 19 to $181 \mathrm{nmol} \mathrm{min}^{-1}$ (mg protein $)^{-1}$ (Table 4). Cells that were activated with $0.55 \mathrm{M}$ sucrose (total osmolality 760 mosmol $\mathrm{kg}^{-1}$ ), in a transport assay medium without $\mathrm{NaCl}$, displayed similar transport activity, i.e. $200 \pm 29 \mathrm{nmol} \mathrm{min}^{-1}$ (mg protein $)^{-1}$. Thus, the activation of BetT depended on osmotic stress and not on $\mathrm{NaCl}$ per se.

\section{Transport properties of BetT mutant proteins}

In Table 4, BetT mutants are given numbers which correspond to the remaining number of residues in BetT. The proteins were expressed in strain AT300 from pAT3derived plasmids and activated with $0.4 \mathrm{M} \mathrm{NaCl}$, as described above.

C-terminally truncated Bet $\mathrm{T}$ proteins with deletions up to 101 residues conferred non-activated transport of choline, which in most cases was similar to that of the wild-type (Table 4). This background activity allowed us to measure their ability to be osmotically activated. A deletion of one (BetT676) or two (BetT675) residues did not influence the osmotic activation, which remained about tenfold, while deletions of six (BetT671) or 12 (BetT665) residues had a pronounced effect on the protein's ability to be activated. Bet T mutants with deletions of 18-101 residues did not display any osmotic activation.

The six C-terminal residues of BetT are Val-Met-Phe-ProAsp-Ala. By in vitro mutagenesis, we made three BetT mutants in which two or three of these amino acids were changed. The substitutions in BetT677-M673A-F674A and BetT677-F764A-P675A-D676G were particularly detrimental to the process of osmotic activation, whereas the substitutions in BetT677-V672A-M673A caused effects that were similar to the deletion of the six C-terminal residues (Table 4 ).

As a control of the measurements of the initial transport activity, we measured the steady-state level of choline accumulation in the cells expressing the wild-type and the mutant BetT proteins. In general, there was a good correlation between the measurements; i.e. only the BetT proteins that displayed osmotic activation provoked a noticeably higher steady-state level of choline accumulation in the presence of $0.4 \mathrm{M} \mathrm{NaCl}$ than in the absence of salt (Table 4).

Kinetic analysis of wild-type BetT and BetT677-M673AF674A were performed with cells grown and tested in M63 with $0.3 \mathrm{M} \mathrm{NaCl}$. The observed $K_{\mathrm{m}}$ values were practically the same, i.e. $3 \pm 1 \mu \mathrm{M}$. This is similar to the $K_{\mathrm{m}}$ value of $8 \mu \mathrm{M}$ determined previously for cells carrying the bet genes on the chromosome (Styrvold et al., 1986). Due to low activities, we were unable to measure any $K_{\mathrm{m}}$ values for cells that had not been activated with $\mathrm{NaCl}$. We also tested if BetT665 $(\Delta 12)$ could be more activated by applying other concentrations of $\mathrm{NaCl}(0.2-0.8 \mathrm{M})$ or longer activation times (up to $20 \mathrm{~min}$ ), but the results were negative (data not shown).

\section{DISCUSSION}

Our conclusion, from the present analyses of $36 \mathrm{PhoA}$ and $15 \mathrm{LacZ}$ fusions at 37 different sites in BetT, is that BetT has the predicted membrane topology of the BCCT family. Besides having 12 membrane-spanning regions, BetT has a small $\mathrm{N}$-terminal domain of about 12 residues and a large $\mathrm{C}$ terminal domain of about 180 residues, both situated in the cytoplasm.

It is now well established that bacterial osmosensors of many kinds sense the osmotic conditions in the cytoplasm, e.g. the transporters ProP of E. coli (Culham et al., 2003), BetP of $C$. glutamicum (Rübenhagen et al., 2001) and OpuA of L. lactis (van der Heide et al., 2001), and the sensor kinases KdpD (Jung et al., 2000) and EnvZ of E. coli (Jung et al., 2001). We observed that BetT mutants carrying C-terminal deletions of 6,12 or 18 amino acid residues displayed a gradual loss in osmotic activation of choline transport. Since the deletion mutants retained the transport activity at low osmolality, these data indicated that the C-terminal domain of 180 residues is involved in the osmoregulation of Bet $\mathrm{T}$ rather than being necessary only for catalytic activity. The deletions of increasing lengths either eliminated a functional part or led to a misfolding of the entire domain, rendering it insensitive to osmotic stress. Similarly, we assume that the detrimental effects on osmotic activation by alanine and glycine substitutions within the last two to six C-terminal residues may be caused by increased flexibility of the tail, which again caused instability of the domain. Similar conclusions were reached by Schiller et al. (2006), who have identified a glutamate residue in the C-terminal end of BetP that is critical for osmosensing by its impact on the folding of this domain. Presumably, the C-terminal domain senses the ionic conditions in the cytoplasm and activates the transporter.

BetT mutants carrying C-terminal deletions of 18-101 residues were permanently locked in a low-activity, noninducible, state. However, the opposite effect of short Cterminal deletions has been reported for the sodium-driven BetP transporter of C. glutamicum, i.e. these truncated transporters are permanently locked in an active state in vivo (Peter et al., 1998; Morbach \& Krämer, 2003). In this respect, ProP of E. coli may seem to behave more similarly to BetT than to BetP. For ProP, it is reported that an amino acid substitution (Arg-488-Ile) which hampers the formation of an antiparallel coiled-coil structure in its C-terminal cytoplasmic domain causes the transporter to be less sensitive to and only transiently activated by osmotic stress in vivo (Culham et al., 2000; Zoetewey et al., 2003). It is 
also noteworthy that the E. coli CaiT transporter of the BCCT family has a deduced C-terminal extension of only ten residues. This transporter, which serves as an Lcarnitine $/ \gamma$-butyrobetaine antiporter in anaerobic respiration, is not osmotically activated (Jung et al., 2002). Since both BetP (Ziegler et al., 2004) and CaiT (Vinothkumar et al., 2006) form trimers in the membrane, it seems likely that Bet T also has a trimeric structure. However, by analogy to CaiT, it seems unlikely that the large C-terminal extensions of BetP and BetT are required for the oligomerization.

The transport activity of wild-type BetT peaked 5 min after spectinomycin-treated cells were subjected to an osmotic upshock. It is therefore tempting to speculate that this was the time when the conditions in the cytoplasm were most favourable for BetT activation. In S. meliloti, it takes 8-10 min to fully activate glycine betaine uptake by BetS. However, unlike BetT, the transport rate of BetS remains constant for at least $3 \mathrm{~h}$ (Boscari et al., 2002). Other transporters are fully activated faster than BetT, e.g. BetP reaches $90 \%$ of maximum activity within $30 \mathrm{~s}$ after osmotic shock (Farwick et al., 1995), whereas ProP of E. coli has an activation half-time of about $1 \mathrm{~min}$ (Milner et al., 1988).

The LacZ fusion linked to Lys-12 displayed a particularly high $\beta$-galactosidase activity. The reason may be that this fusion produced a soluble protein. An additional explanation is that the region of betT encoding amino acid residues 7-30 may form a stem-loop structure of 29 bp with only two mismatches in mRNA (Lamark et al., 1991). This putative structure, which may be involved in the regulation of BetT expression, was present in all fusions except the Lys12 fusion. A similar reduction in the expression level of CodB-LacZ hybrid proteins of E. coli has previously been observed for fusion points which are situated after a weak transcriptional terminator (Danielsen et al., 1995).

It is also noteworthy that our analysis of BetT-LacZ fusions showed that the bet $T$ promoter itself (without BetI) was down-regulated about tenfold in cells grown in LB (410 mosmol kg ${ }^{-1}$ ) compared with cells grown in halfstrength M63 (160 mosmol kg ${ }^{-1}$ ) (Table 3). This aspect of bet $T$ regulation, which is not linked to hyperosmotic stress, has not been revealed previously.

\section{ACKNOWLEDGEMENTS}

We thank J. Neuhard, A. J. Pittard and C. S. Young for providing bacterial strains and plasmids. We thank P. Bjørsvik and M. Aune for assistance with the Western blot analyses and A. Bremnes for technical assistance with figures in this manuscript. This work was supported by a grant from the Research Council of Norway.

\section{REFERENCES}

Adams, C. W., Forrest, M. E., Cohen, S. N. \& Beatty, J. T. (1989). Structural and functional analysis of transcriptional control of the Rhodobacter capsulatus puf operon. J Bacteriol 171, 473-482.
Andresen, P. A., Kaasen, I., Styrvold, O. B., Boulnois, G. \& Strøm, A. R. (1988). Molecular cloning, physical mapping and expression of the bet genes governing the osmoregulatory choline-glycine betaine pathway of Escherichia coli. J Gen Microbiol 134, 1737-1746.

Bochner, B. R., Huang, H. C., Schieven, G. L. \& Ames, B. N. (1980). Positive selection for loss of tetracycline resistance. J Bacteriol 143, 926-933.

Boscari, A., Mandon, K., Dupont, L., Poggi, M. C. \& Le Rudulier, D. (2002). BetS is a major glycine betaine/proline betaine transporter required for early osmotic adjustment in Sinorizobium meliloti. J Bacteriol 184, 2654-2663.

Calamia, J. \& Manoil, C. (1990). lac permease of Escherichia coli: topology and sequence elements promoting membrane insertion. Proc Natl Acad Sci U S A 87, 4937-4941.

Chung, C. T., Niemela, S. L. \& Miller, R. H. (1989). One-step preparation of competent Escherichia coli: transformation and storage of bacterial cells in the same solution. Proc Natl Acad Sci U S A 86, 2172-2175.

Culham, D. E., Tripet, B., Racher, K. I., Voegele, R. T., Hodges, R. S. \& Wood, J. M. (2000). The role of the carboxyl terminal $\alpha$-helical coiled-coil domain in osmosensing by transporter ProP of Escherichia coli. J Mol Recognit 13, 309-322.

Culham, D. E., Henderson, J., Crane, R. A. \& Wood, J. M. (2003). Osmosensor ProP of Escherichia coli responds to the concentration, chemistry, and molecular size of osmolytes in the proteoliposome lumen. Biochemistry 42, 410-420.

Danielsen, S., Boyd, D. \& Neuhard, J. (1995). Membrane topology analysis of the Escherichia coli cytosine permease. Microbiology 141, 2905-2913.

Derman, A. I. \& Beckwith, J. (1995). Escherichia coli alkaline phosphatase localized to the cytoplasm slowly acquires enzymatic activity in cells whose growth has been suspended: a caution for gene fusion studies. J Bacteriol 177, 3764-3770.

Fan, X., Pericone, C. D., Lysenko, E., Goldfine, H. \& Weiser, J. N. (2003). Multiple mechanisms for choline transport and utilization in Haemophilus influenzae. Mol Microbiol 50, 537-548.

Farwick, M., Siewe, R. M. \& Krämer, R. (1995). Glycine betaine uptake after hyperosmotic shift in Corynebacterium glutamicum. J Bacteriol 177, 4690-4695.

Froshauer, S., Green, G. N., Boyd, D., McGovern, K. \& Beckwith, J. (1988). Genetic analysis of the membrane insertion and topology of MalF, a cytoplasmic membrane protein of Escherichia coli. J Mol Biol 200, 501-511.

Giæver, H. M., Styrvold, O. B., Kaasen, I. \& Strøm, A. R. (1988). Biochemical and genetic characterization of osmoregulatory trehalose synthesis in Escherichia coli. J Bacteriol 170, 2841-2849.

Hanahan, D., Jessee, J. \& Bloom, F. R. (1991). Plasmid transformation of Escherichia coli and other bacteria. Methods Enzymol 204, 63-113.

Hillar, A., Culham, D. E., Vernikovska, Y. I., Wood, J. M. \& Boggs, J. M. (2005). Formation of an antiparallel, intermolecular coiled coil is associated with in vivo dimerization of osmosensor and osmoprotectant transporter ProP in Escherichia coli. Biochemistry 44, 10170-10180.

Jung, K., Veen, M. \& Altendorf, K. (2000). $\mathrm{K}^{+}$and ionic strength directly influence the autophosphorylation activity of the putative turgor sensor KdpD of Escherichia coli. J Biol Chem 275, 40142-40147.

Jung, K., Hamann, K. \& Revermann, A. (2001). $\mathrm{K}^{+}$stimulates specifically the autokinase activity of purified and reconstituted EnvZ of Escherichia coli. J Biol Chem 276, 40896-40902.

Jung, H., Buchholz, M., Clausen, J., Nietschke, M., Revermann, A., Schmid, R. \& Jung, K. (2002). CaiT of Escherichia coli, a new 
transporter catalysing L-carnitine $/ \gamma$-butyrobetaine exchange. J Biol Chem 277, 39251-39258.

Kappes, R. M., Kempf, B. \& Bremer, E. (1996). Three transport systems for the osmoprotectant glycine betaine operate in Bacillus subtilis: characterization of OpuD. J Bacteriol 178, 5071-5079.

Krogh, A., Larsson, B., von Heijne, G. \& Sonnhammer, E. L. L. (2001). Predicting transmembrane protein topology with a Hidden Markov Model: application to complete genomes. J Mol Biol 305, 567-580.

Lamark, T., Kaasen, I., Eshoo, M. W., Falkenberg, P., McDougall, J. \& Strøm, A. R. (1991). DNA sequence and analysis of the bet genes encoding the osmoregulatory choline-glycine betaine pathway of Escherichia coli. Mol Microbiol 5, 1049-1064.

Lamark, T., Røkenes, T. P., McDougall, J. \& Strøm, A. R. (1996). The complex bet promoters of Escherichia coli: regulation by oxygen (ArcA), choline (BetI), and osmotic stress. J Bacteriol 178, 1655-1662.

Landfald, B. \& Strom, A. R. (1986). Choline-glycine betaine pathway confers a high level of osmotic tolerance in Escherichia coli. J Bacteriol 165, 849-855.

Manoil, C. (1991). Analysis of membrane protein topology using alkaline phosphatase and $\beta$-galactosidase gene fusions. Methods Cell Biol 34, 61-75.

Manoil, C. \& Beckwith, J. (1986). A genetic approach to analyzing membrane protein topology. Science 233, 1403-1408.

May, G., Faatz, E., Villarejo, M. \& Bremer, E. (1986). Binding protein dependent transport of glycine betaine and its osmotic regulation in Escherichia coli K12. Mol Gen Genet 205, 225-233.

Miller, J. H. (1972). Experiments in Molecular Genetics. Cold Spring Harbor, NY: Cold Spring Harbor Laboratory.

Milner, J. L., Grothe, S. \& Wood, J. M. (1988). Proline porter II is activated by a hyperosmotic shift in both whole cells and membrane vesicles of Escherichia coli K12. J Biol Chem 263, 14900-14905.

Morbach, S. \& Krämer, R. (2003). Impact of transport processes in the osmotic response of Corynebacterium glutamicum. J Biotechnol 104, 69-75.

Peter, H., Burkovski, A. \& Krämer, R. (1996). Isolation, characterization, and expression of the Corynebacterium glutamicum betP gene, encoding the transport system for the compatible solute glycine betaine. J Bacteriol 178, 5229-5234.

Peter, H., Burkovski, A. \& Krämer, R. (1998). Osmo-sensing by Nand C-terminal extensions of the glycine betaine uptake system BetP of Corynebacterium glutamicum. J Biol Chem 273, 2567-2574.

Racher, K. I., Voegele, R. T., Marshall, E. V., Culham, D. E., Wood, J. M., Jung, H., Bacon, M., Cairns, M. T., Ferguson, S. M. \& other authors (1999). Purification and reconstitution of an osmosensor: transporter ProP of Escherichia coli senses and responds to osmotic shifts. Biochemistry 38, 1676-1684.

Røkenes, T. P., Lamark, T. \& Strøm, A. R. (1996). DNA-binding properties of the BetI repressor protein of Escherichia coli: the inducer choline stimulates BetI-DNA complex formation. J Bacteriol 178, 1663-1670.

Rübenhagen, R., Rönsch, H., Jung, H., Krämer, R. \& Morbach, S. (2000). Osmosensor and osmoregulator properties of the betaine carrier BetP from Corynebacterium glutamicum in proteoliposomes. J Biol Chem 275, 735-741.

Rübenhagen, R., Morbach, S. \& Krämer, R. (2001). The osmoreactive betaine carrier BetP from Corynebacterium glutamicum is a sensor for cytoplasmic $\mathrm{K}^{+}$. EMBO J 20, 5412-5420.

Saier, M. H., Eng, B. H., Fard, S., Garg, J., Haggerty, D. A., Hutchinson, W. J., Jack, D. L., Lai, E. C., Liu, H. J. \& other authors (1999). Phylogenetic characterization of novel transport protein families revealed by genome analyses. Biochim Biophys Acta 1422, 1-56.

Sambrook, J., Fritsch, E. F. \& Maniatis, T. (1989). Molecular Cloning: a Laboratory Manual, 2nd edn. Cold Spring Harbor, NY: Cold Spring Harbor Laboratory.

Schiller, D., Ott, V., Krämer, R. \& Morbach, S. (2006). Influence of membrane composition on osmosensing by the betaine carrier BetP from Corynebacterium glutamicum. J Biol Chem 281, 7737-7746.

Schweizer, H. \& Boos, W. (1983). Transfer of the $\Delta$ (argF-lac)U169 mutation between Escherichia coli strains by selection for a closely linked Tn10 insertion. Mol Gen Genet 192, 293-294.

Styrvold, O. B., Falkenberg, P., Landfald, B., Eshoo, M. W., Bjornsen, T. \& Strøm, A. R. (1986). Selection, mapping, and characterisation of osmoregulatory mutants of Escherichia coli blocked in the choline-glycine betaine pathway. J Bacteriol 165, 856-863.

van der Heide, T. \& Poolman, B. (2000). Osmoregulated ABCtransport system of Lactococcus lactis senses water stress via changes in the physical state of the membrane. Proc Natl Acad Sci U S A 97, 7102-7106.

van der Heide, T., Stuart, M. C. A. \& Poolman, B. (2001). On the osmotic signal and osmosensing mechanism of an $\mathrm{ABC}$ transport system for glycine betaine. EMBO J 20, 7022-7032.

Varga, A. R. \& Kaplan, S. (1989). Construction, expression, and localization of a CycA::PhoA fusion protein in Rhodobacter sphaeriodes and Escherichia coli. J Bacteriol 171, 5830-5839.

Vinothkumar, K. R., Raunser, S., Jung, H. \& Kühlbrandt, W. (2006). Oligomeric structure of the carnitine transporter CaiT from Escherichia coli. J Biol Chem 281, 4795-4801.

Ziegler, C., Morbach, S., Schiller, D., Krämer, R., Tziatzios, C., Schubert, D. \& Kühlbrandt, W. (2004). Projection structure and oligomeric state of the osmoregulated sodium/glycine betaine synporter BetP of Corynebacterium glutamicum. J Mol Biol 337, 1137-1147.

Zoetewey, D. L., Tripet, B. P., Kutateladze, T. G., Overduin, M. J., Wood, J. M. \& Hodges, R. S. (2003). Solution structure of the Cterminal antiparallel coiled-coil domain from Escherichia coli osmosensor ProP. J Mol Biol 334, 1063-1076.

Edited by: J. Green 